\title{
Digital Health: New Approaches in Hypertension Management
}

\author{
Jamie Kitt', Rachael Fox ${ }^{2}$, Katherine L Tucker ${ }^{3 *}$ \\ 'Radcliffe Department of Medicine (Cardiovascular Division), University of Oxford, UK \\ ${ }^{2}$ University of Melbourne, Melbourne, Australia \\ ${ }^{3}$ Nuffield Department of Primary Care, University of Oxford, UK
}

\section{Article Info}

\section{Article Notes}

Received: January 21, 2020

Accepted: February 11, 2020

\section{${ }^{*}$ Correspondence:}

Dr. Katherine Tucker, Nuffield Department of Primary Care,

University of Oxford, Radcliffe Primary Care, Radcliffe

Observatory Quarter, Woodstock Road, OX2 6GG, UK;

Telephone No: +44 (0)1865 617852;

Email: Katherine.tucker@phc.ox.ac.uk.

C 2020 Tucker KL. This article is distributed under the terms of the Creative Commons Attribution 4.0 International License.

\section{Keywords:}

Self-monitoring

Hypertension

Smart-phones

Apps

Telemonitoring

Self-management

\section{Abstract}

Hypertension is a key risk factor for cardiovascular disease. Globally, approximately a third of people with hypertension remain undiagnosed, and of those diagnosed, about half are not taking antihypertensive medication. The World Health Organization has estimated that globally hypertension directly or indirectly causes the deaths of at least nine million people every year.

There is a trend towards self-monitoring of blood pressure (BP), where patients are empowered to be involved in hypertension screening and diagnosis. Novel technology, including smartphones and Blue-tooth ${ }^{\circledR}$ enabled telemonitoring, are new tools that are likely to be increasingly important in hypertension management. Several studies have shown the benefit of selfmonitoring of BP coupled with co-interventions (such as telemonitoring) in improving BP management. However, these new technologies must be properly assessed and clinically validated prior to widespread implementation in the general population, or within special groups. In this mini-review, we examine how technology might improve the detection and management of hypertension.

\section{Introduction}

Treating hypertension has been shown to result in marked reductions in the risk of long-term cardiovascular disease ${ }^{1,2}$. Despite strong evidence for such treatment, it is widely recognised that many people remain un-diagnosed (between a third and a half of patients), indicating the need for better screening ${ }^{3}$, and $40 \%$ of those on hypertensive registries remain sub-optimally controlled ${ }^{4}$. New approaches, including new technologies, are needed to improve screening, detection and control of raised blood pressure (BP).

The widespread accessibility of smartphones and mobile health applications bring with them a new potential for the ubiquitous monitoring of parameters such as blood pressure. Such technology can be used for self-monitoring, telemonitoring, as part of virtual clinics and/or in artificial intelligence (AI)-assisted management. All of these can be done with a traditional cuff-based monitor (with or without Bluetooth $($ ) or with novel cuffless blood pressure monitoring devices.

A vital issue with both smartphones/tablet apps and novel cuffless devices is the lack of an agreed standard for validating the technology. This is a rapidly expanding field, with $>180$ apps now existing relating to blood pressure monitoring. These devices are even foraying into derived measurement. For example, Cardiogram ${ }^{\circledR}{ }^{5}$ on the Apple ${ }^{\circledR}$ watch has been evaluated for its efficacy at using deep learning algorithms to predict hypertension from inputs of heart rate and step count. However, the involvement 
of medical experts in the development process has only taken place in $<5 \%$ of blood pressure apps ${ }^{6}$. At present, no mobile apps have obtained approval for use as BP measuring/diagnostic devices by the US Food and Drug Administration or European Commission, though clinic validation is now being sought by some manufacturers ${ }^{7,8}$. As a result, there is currently limited incorporation of this technology into clinical practice ${ }^{9}$.

The two most widely accepted, utilised and promising digital health technologies are self-monitoring and telemonitoring, both of which are explored further below. How these may fit into future models of care for hypertension is summarised in Figure 1.

\section{Self-Monitoring}

A recent systematic review of blood pressure selfmonitoring by Sheppard et $a l^{20}$, which included 22 eligible trials and 6,522 participants showed that self-monitoring was associated with an improvement in clinic systolic BP vs. standard care at a 12 -month time-point $(-3.12 \mathrm{~mm}$ $\mathrm{Hg}$, [95\% confidence intervals $-4.78,-1.46 \mathrm{~mm} \mathrm{Hg}$. This

Figure 1: How digital technology may fit into future models of care. BP: Blood Pressure; ABPM: Ambulatory Blood Pressure Monitoring; HBPM: Home Blood Pressure Monitoring; PPG: Photoplethysmogram

\section{USUAL CARE}

\section{Screening}

Blood pressure measurement is recommended at least 5 yearly among normotensive adults. ${ }^{1}$

Hypertension is largely identified in a primary care clinic setting by routine or opportunistic BP measurement.

\section{Diagnosis}

Ambulatory blood pressure monitoring (ABPM) is regarded as the most accurate way to confirm a diagnosis of hypertension. ${ }^{1}$ Ambulatory BP monitors are typically portable, automated cuffs that inflate at regular intervals.

Alternatively, home blood pressure monitoring (HBPM) may be used to confirm a diagnosis of hypertension. This requires two consecutive measures at least one minute apart, morning and evening for at least four days. ${ }^{1}$

\section{Management and monitoring}

Hypertension is commonly managed in primary health care clinics. The physician reviews blood pressure, assesses risk of cardiovascular disease, offers lifestyle advice, and may commence antihypertensive treatment. Patients may bring in home readings if monitoring $\mathrm{BP}$ at home.

If a patient is on antihypertensive treatment, this is titrated by the physician based on factors such as blood pressure control, risk of cardiovascular disease, comorbidities and medication side effects. Ideal targets may vary depending on comorbid conditions including type two diabetes or chronic kidney disease. ${ }^{1}$

Management also involves screening renal, retinal and cardiovascular function for signs of target organ damage. ${ }^{1}$

\section{POTENTIAL ROLE FOR DIGITAL TECHNOLOGY}

Self-screening with automated BP cuffs

Use of automated blood pressure cuffs externally to physician consults, at home or in public, to screen normotensive individuals.

\section{Self-screening with smartphone apps \\ Variety of health apps available that monitor BP, and may alert user if abnormal}

\section{Self-monitoring with automated BP cuffs}

Traditional HBPM for diagnostic purposes may also incorporate newer digital technologies, such as

Bluetooth, to enable readings to be uploaded onto a device, such as a smartphone.

\section{Self monitoring with cuff-less BP} monitoring devices

Novel wearable devices, such as wrist watches, can monitor BP by utilising ECG and PPG signals.

Additionally, smartphone apps have been developed with similar technologies to monitor BP and aid diagnosis.

\section{Self-monitoring and management with automated BP cuffs}

Patient takes readings out of office with automated BP machine which may be linked to Bluetooth to allow transmission of readings to a device e.g smartphone. Self-management involves titration of medication based on these results.

\section{Telemonitoring}

Data from self-monitoring readings is automatically transferred to the physician/health care worker. Transfer may be conducted over email, text message, or apps with a Cloud upload.

\section{Virtual clinics}

Clinic appointment is conducted through online interaction.

The patient my enter information and blood pressure readings then utilised by the physician to adjust management. 
Table 1: A summary of digital technologies alongside some of the key advantages and disadvantages of each. BP: Blood Pressure; HCP: Health Care Professionals; PPG: Photoplethysmogram

\begin{tabular}{|c|c|c|c|c|}
\hline $\begin{array}{l}\text { Digital Health } \\
\text { Technology }\end{array}$ & Description & Examples & Advantages & Disadvantages \\
\hline $\begin{array}{l}\text { Self-screening/ } \\
\text { monitoring BP } \\
\text { cuffs }\end{array}$ & $\begin{array}{l}\text { Patients measure BP outside of physi- } \\
\text { cian consults with validated automatic } \\
\text { sphygmomanometers. } \\
\text { Can be used for screening, diagnosis or } \\
\text { management. Management (termed } \\
\text { self-management) is possible by shar- } \\
\text { ing self-monitored readings with HCPs } \\
\text { to enable titration of medications. }\end{array}$ & $\begin{array}{l}\text { Home blood pressure monitors or } \\
\text { public blood pressure cuffs in settings } \\
\text { including pharmacies, work places } \\
\text { and grocery stores }{ }^{10-12} \text {. } \\
\text { May utilise Bluetooth }{ }^{\circledR} \text { and smart- } \\
\text { phone applications for transmission } \\
\text { of readings. More effective when } \\
\text { combined with co-interventions } \\
\text { such as self-management or lifestyle } \\
\text { counselling }{ }^{12} \text {. }\end{array}$ & $\begin{array}{l}\text { No training required, } \\
\text { low cost, patient } \\
\text { autonomy, convenient, } \\
\text { increased detection of } \\
\text { hypertension }^{10-12} \text {. }\end{array}$ & $\begin{array}{l}\text { Data privacy concerns, } \\
\text { lack of awareness of } \\
\text { the technology, lack of } \\
\text { education, and } 50 \% \text { of } \\
\text { patients do not tell clini- } \\
\text { cians they are self-mon- } \\
\text { itoring or share the } \\
\text { readings in a meaningful } \\
\text { manner }^{13} \text {. }\end{array}$ \\
\hline $\begin{array}{l}\text { Cuff-less ambu- } \\
\text { latory BP moni- } \\
\text { toring devices }\end{array}$ & $\begin{array}{l}\text { Wearable devices providing continuous } \\
\text { BP monitoring with applications in } \\
\text { diagnosis and management. } \\
\text { Devices may utilise ECG signals, PPG } \\
\text { signals or more commonly a combi- } \\
\text { nation of the two to determine BP. } \\
\text { Machine learning and neural networks } \\
\text { have also been incorporated in some } \\
\text { devices }^{14} \text {. }\end{array}$ & $\begin{array}{l}\text { Sensors may be embedded in wear- } \\
\text { able devices including wrist watches, } \\
\text { T-shirts, heart rate belts, glasses } \\
\text { frames or placed behind the ears }{ }^{14} \text {. } \\
\text { Data from cuff-less BP monitoring } \\
\text { devices may be transmitted to smart- } \\
\text { phone applications (see telemonitor- } \\
\text { ing below) }{ }^{14} \text {. }\end{array}$ & $\begin{array}{l}\text { Continuous monitoring } \\
\text { of BP without disrup- } \\
\text { tion to daily activities, } \\
\text { portable, convenient, } \\
\text { discrete }^{14} \text {. }\end{array}$ & $\begin{array}{l}\text { Lack of clinical valida- } \\
\text { tion and standardisa- } \\
\text { tion, variable accuracy } \\
\text { of devices }{ }^{14} \text {. }\end{array}$ \\
\hline $\begin{array}{l}\text { Mobile } \\
\text { health(mHealth) } \\
\text { and smartphone } \\
\text { apps }\end{array}$ & $\begin{array}{l}\text { Potential use for screening, diagno- } \\
\text { sis and management. Apps record } \\
\text { BP readings and may incorporate } \\
\text { additional features such as reminder } \\
\text { functions, logbooks or information on } \\
\text { lifestyle management. Can be used in } \\
\text { conjunction with Bluetooth }{ }^{\circledR} \text { BP cuffs/ } \\
\text { cuff-less devices as part of telemon- } \\
\text { itoring if data export functions are } \\
\text { available. }\end{array}$ & $\begin{array}{l}\text { Over } 180 \text { apps existing to measure } \\
\text { blood pressure }{ }^{6} \text {. Examples include } \\
\text { AMICOMED }^{\circledR} \text { for Android systems and } \\
\text { Bloeddruk }^{\circledR} \text { for iOS devices. }\end{array}$ & $\begin{array}{l}\text { Convenient, accessi- } \\
\text { bility, low cost, patient } \\
\text { autonomy, widespread } \\
\text { ownership of smart- } \\
\text { phones }^{6} \text {. }\end{array}$ & $\begin{array}{l}\text { Lack of clinical valida- } \\
\text { tion and standardisa- } \\
\text { tion, majority are of } \\
\text { poor quality, inaccuracy, } \\
\text { minimal involvement } \\
\text { of healthcare agencies } \\
\text { in development, data } \\
\text { privacy issues, more } \\
\text { limited use in elderly } \\
\text { populations }\end{array}$ \\
\hline Telemonitoring & $\begin{array}{l}\text { Tele-monitoring is a particular applica- } \\
\text { tion of telemedicine-the transfer of } \\
\text { data remotely-which in this case con- } \\
\text { sists of automatic data transmission of } \\
\text { BP readings. This can allow clinicians to } \\
\text { titrate medication based on self-moni- } \\
\text { toring results }{ }^{16,17} \text {. }\end{array}$ & $\begin{array}{l}\text { Several systems available; This can } \\
\text { be done by text messages, e-mail or } \\
\text { apps via a Cloud }{ }^{\circledR} \text { upload }^{17} \text {. Additional } \\
\text { features such as reminders for BP } \\
\text { measurement or tools to enhance } \\
\text { medication adherence may be includ- } \\
\text { ed }^{16,17} \text {. }\end{array}$ & $\begin{array}{l}\text { No training required, } \\
\text { patient autonomy, con- } \\
\text { venient, increased de- } \\
\text { tection of hypertension, } \\
\text { ensures collaboration } \\
\text { with treating physician, } \\
\text { increased self-awareness } \\
\text { of health }{ }^{17} \text {. }\end{array}$ & $\begin{array}{l}\text { Improves chances of } \\
\text { BP control compared to } \\
\text { self-monitoring alone }{ }^{16} \text {, } \\
\text { has higher costs associ- } \\
\text { ated than self-monitor- } \\
\text { ing alone }{ }^{16,17} \text {. }\end{array}$ \\
\hline Virtual clinics & $\begin{array}{l}\text { Structured online interactions between } \\
\text { a patient and health professional to } \\
\text { provide follow up for face-to-face } \\
\text { visits }^{18,19} \text {. }\end{array}$ & $\begin{array}{l}\text { Utilised as follow up to an in-person } \\
\text { visit. Patients are given access via } \\
\text { an email or link to a secure virtual } \\
\text { visit website through which they } \\
\text { are directed to enter blood pressure } \\
\text { readings, complete set questions or } \\
\text { type issues as free text. The clinician } \\
\text { reviews this data and responds with } \\
\text { management decisions and a plan for } \\
\text { follow up }{ }^{18,19} \text {. }\end{array}$ & $\begin{array}{l}\text { Reduces number of face- } \\
\text { to-face primary care } \\
\text { office visits required, } \\
\text { convenient, time effi- } \\
\text { cient, no difference in } \\
\text { SBP control compared to } \\
\text { specialist visits }{ }^{18,19} \text {. }\end{array}$ & $\begin{array}{l}\text { Studies limited to } \\
\text { patients with reasonably } \\
\text { well controlled hyper- } \\
\text { tension, requires access } \\
\text { to internet connection } \\
\text { and equipped devices }{ }^{18} \text {. }\end{array}$ \\
\hline
\end{tabular}

remained true irrespective of the number of hypertensionrelated co-morbidities. This review also found, that intense interventions (such as those with self-management, tailored education, 1:1 support from a health care professional or pharmacist) were more effective than low-intensity interventions in certain patients. This included those with obesity $(P<0.001$ for all outcomes, OR for likelihood of uncontrolled clinic BP at follow up 1.12 [low intensity] v. OR 0.49 [high intensity]). The same was true for stroke patients $(P<0.004$ for BP control outcome only with OR for likelihood of uncontrolled clinic BP at follow up 1.14 [low intensity] v. OR 0.37 [high intensity]). This highlights the importance of co-intervention support for conditions such as these. This effect was not observed in patients with coronary heart disease, diabetes, or chronic kidney disease, potentially due to lack of power, as there was some evidence to suggest that self-monitoring is effective in these patients in combination with high-intensity cointerventions ${ }^{20}$.

\section{Telemonitoring}

Randomised controlled trials over the past $10-15$ 
years have investigated whether the home blood pressure telemonitoring is associated with improvements in healthcare outcomes ${ }^{17}$. In a large meta-analysis ${ }^{17}$, all studies included demonstrated excellent acceptance of the technology by both doctors and patients, as well as high levels of adherence to telemonitoring programs. Home BP monitoring has in fact, been included in the NICE guidelines for adult hypertension since $2011^{21}$. Until recently, the key evidence missing from trials of telemonitoring was whether the use of such data by clinicians actually led to lower blood pressure. In 2018, the TASMINH4 trial $^{16}$ randomised primary care physicians to utilising self-monitored BP readings to titrate antihypertensives, with or without telemonitoring vs. relying on standard clinic readings alone. This trial demonstrated better blood pressure control in the arm using selfmonitored readings compared to the arm using clinic readings alone. The telemonitoring group also achieved a lower BP more quickly than self-monitoring alone, but overall these readings were not significantly different at the primary end of 12 months.

\section{Implementation of Novel Digital Health Technology in Special Groups}

\section{Telemonitoring and heart failure}

Several studies have demonstrated the applicability of remote telemonitoring beyond optimising blood pressure control in patients who often have several other cardiac co-morbidities. One randomised, controlled and openlabel clinical trial in 40 patients with chronic heart failure in north-western Mexico, demonstrated telemonitoring reduced their weight by an average of $1.4 \mathrm{~kg}(\mathrm{p}=0.01$ with Mann-Whitney U test), improved symptom control, and lowered their systolic blood pressure (SBP) from $133 \pm 19$ $\mathrm{mmHg}$ to $125 \pm 10 \mathrm{mmHg}$. This translated into a cost of care decrease of more than $50 \%$ compared to traditional medical consultation (traditional medical consultation group was observed to have an average cost of $\$ 14,185.90$ Mexican pesos per patient, in contrast with the telemonitored group, $\$ 8642.10$, with a real difference in savings by patient of $\$ 5543.00$ Mexican pesos). Furthermore, admission to the emergency room was avoided in $100 \%$ of the telemonitored patients at the end of 12 weeks follow up ${ }^{22}$.

In another study, 534 patients suffering from heart failure used telemonitoring to upload daily measurements of blood pressure, pulse, SpO2 and weight. Changes in the European heart failure self-care behaviour scale questionnaire and EQ-5D-5L quality of life questionnaire revealed a general, positive effect of by increasing selfawareness of participants about their condition ${ }^{23}$.

Several other small studies have been less convincing in demonstrating the benefit of telemonitoring ${ }^{24}$ but the results of larger RCTs are anticipated including HeartMan ${ }^{25}$, and in the UK the SUPPORT-HF 2 study, which should determine if telemonitoring with information technologysupported specialist management is more effective in optimising medical therapy than home monitoring alone for patients with heart failure ${ }^{26}$.

\section{Telemonitoring in atrial fibrillation}

Hypertension is a risk factor for atrial fibrillation (AF), and approximately $50 \%$ of those with $\mathrm{AF}$ have hypertension ${ }^{27}$, making blood pressure measurement an important aspect of care in these patients. However, it is widely recognised that there are severe limitations to current methods of $\mathrm{BP}$ monitoring in those with $\mathrm{AF}^{28}$. Validation studies of automated blood pressure devices often list $\mathrm{AF}$ as an exclusion criteria, resulting in a lack of evidence regarding the accuracy of these devices. This in turn, makes reliable out-of-office BP measurement, including home and ambulatory BP monitoring, more difficult in this population. As a result, $\mathrm{NICE}^{21}$ and European guidelines ${ }^{29}$ currently both recommend manual measurement of blood pressure when AF is present, there may well be a role for novel digital technology in assisting screening and diagnosis of AF itself however, and recent publications such as the APPLE HEART study in NEJM last year as testament to their potential ${ }^{30}$. In this study, more than 419,000 participants were recruited, 2,161 received abnormal notifications from their Apple watch $\AA$ and only $64 \%$ of that 2,161 completed the end of study survey. In those that did receive irregular pulse notifications, the positive predictive value was 0.84 (95\% CI, 0.76 to 0.92 ) for observing atrial fibrillation on the ECG simultaneously with a subsequent irregular pulse notification and 0.71 (97.5\% CI, 0.69 to 0.74 ) for observing atrial fibrillation on the ECG simultaneously with a subsequent irregular tachogram. This study illustrates both the potential benefit and risks of such technology. Digital-tech studies can attract huge patient numbers needed when event rates may be low, but are associated with participant retention and dropout issues as well as issues with reliability and validation of the 'app' against current 'gold standard' screening/diagnostic methods e.g. in the APPLE HEART study only 450/2161 (21\%) actually returned a confirmatory ECG patch sent to them that was of diagnostic quality. This puts participants at risk of an incorrect diagnosis and does not meet current validation method standards.

\section{Pregnancy}

In the UK, women are empowered to look after their own medical notes throughout pregnancy. As maternity notes move to a digital platform, this offers additional opportunities for digital health technology in this group. In the future, women may be able to feed data into the system (e.g. blood glucose and BP) allowing the above technologies to tie in with electronic records ${ }^{31,32}$. 
Blood pressure monitoring: Self-monitoring of BP in pregnancy has been shown to be feasible and to have the potential to detect hypertensive disorders sooner than standard care $^{33}$. A recent survey found that many pregnant women are already self-monitoring their BP, although they may not always discuss their readings with health care professionals. (Tucker et al, in preparation). Self-monitoring opens up the possibility of re-organising antenatal care and research into the potential for women to monitor their own BP and receive their care in groups is ongoing ${ }^{34-36}$. Two large trials of BP monitoring have just finished recruiting higher risk and hypertensive women to assess whether self-monitoring improves the detection and/or control of hypertension in pregnancy. (BUMP1 and BUMP2, https://clinicaltrials.gov/ NCT033341493 ${ }^{37}$. The results of these trials will make the place of self-monitoring in pregnancy clearer.

Gestational diabetes: Self-monitoring of glucose in gestational diabetes also appears feasible, acceptable and beneficial. In one randomised trial of smart phone app based self-monitoring vs. standard clinical care, participants reported higher satisfaction with care (intervention: median 43, IQR 39-46; control: median 44.5, IQR 41-46, $p=0.049)$, preterm birth occurred less frequently (5/101, $5.0 \%$ vs $13 / 102,12.7 \%$; OR $0.36,95 \%$ CI $0.12-1.01$ ) and there were also fewer caesarean deliveries in the selfmonitoring group ${ }^{31}$. The benefits of telemedicine in diabetes in pregnancy are reinforced in a recent systematic review and meta-analysis, which demonstrated a modest but statistically significant improvement in HbA1c associated with the use of a telemedicine technology ${ }^{32}$.

\section{Postpartum monitoring}

A recent randomised feasibility trial on self-management of BP following a hypertensive pregnancy demonstrated self-management (where women titrate their own hypertensive medications based on home readings) has the potential to make a significant improvement in BP control during the post-partum period ${ }^{13}$. The trial used a purposedesigned app that allowed women to record self-monitored $\mathrm{BP}$, to receive reminders to monitor their $\mathrm{BP}$, and provided real-time automated medication titration feedback based on NICE guidance at that time. The technology was found to be acceptable, with $85 \%$ adherence, accurate, and resulted in a diastolic blood pressure benefit of mean $-4.5 \mathrm{mmHg}$ at 6 months' post-partum. A recent qualitative paper based on this work also found that this approach was empowering and valued by the vast majority of participants ${ }^{38}$.

Self and telemonitoring also appear to offer benefits in this group of patients in two other areas of prenatal care based on the current literature: a) cardiotocography; b) prenatal ultrasound. The majority of publications are pilot projects on; remote consultation, education, coaching, screening, monitoring and selective booking. These studies mostly report potential medical and/or economic benefits by mobile health applications over conventional care for very specific situations, indications and locations ${ }^{39}$.

\section{Conclusion}

Current research suggests that novel digital health technology might support improved detection and management of hypertension and its related comorbidities. With support, patients can be empowered to be more involved with their health and several studies have shown the benefit of telemonitoring and self-management of hypertension and its associated comorbidities. However, new technologies must be properly assessed and clinically validated prior to implementation and suitable validation processes needed to be agreed. Further research is underway that should improve our understanding of the role of these technologies.

\section{Acknowledgements}

KT is currently funded through a National Institute for Health Research (NIHR) programme for applied research (RP-PG-0614-20005). JK is funded through a British Heart Foundation Clinical Research Training Fellowship (BHF Grant number FS/19/7/34148). KT and JK have received funding from the National Institute for Health Research (NIHR) Collaboration for Leadership in Applied Health Research and Care Oxford (NIHR CLAHRC Oxford) now recommissioned as NIHR Applied Research Collaboration Oxford and Thames Valley. The views expressed in this publication are those of the authors and not necessarily those of the NHS, the National Institute for Health Research or the Department of Health and Social Care.

\section{References}

1. Law MR, Morris JK, Wald NJ. Use of blood pressure lowering drugs in the prevention of cardiovascular disease: Meta-analysis of 147 randomised trials in the context of expectations from prospective epidemiological studies. BMJ. 2009; 338(7705): 1245.

2. Collins R, Peto R, MacMahon S, et al. Blood pressure, stroke, and coronary heart disease. Part 2, short-term reductions in blood pressure: overview of randomised drug trials in their epidemiological context. Lancet. 1990; 335(8693): 827-38.

3. National Statistics. Health Survey for England - 2011, Health, social care and lifestyles [Internet]. 2012. Available from: https://digital. nhs.uk/data-and-information/publications/statistical/healthsurvey-for-england/health-survey-for-england-2011-health-socialcare-and-lifestyles

4. Wolf-Maier K, Cooper RS, Kramer H, et al. Hypertension Treatment and Control in Five European Countries, Canada, and the United States. Vol 43 Hypertension. 2004; 10-7.

5. Tison GH, Singh AC, Ohashi DA, et al. Abstract 21042: Cardiovascular Risk Stratification Using Off-the-Shelf Wearables and a Multi-Task Deep Learning Algorithm. Circulation. 2017.

6. Jamaladin $\mathrm{H}$, van de Belt $\mathrm{TH}$, Luijpers $\mathrm{LCH}$, et al. Mobile apps for blood pressure monitoring: Systematic search in app stores and content analysis. JMIR mHealth uHealth. 2018; 6(11). 
7. Plante TB, Urrea B, Blumenthal RS, et al. Validation of the instant blood pressure smartphone app. JAMA Internal Medicine. 2016; Vol 176: 700-2.

8. Plante TB, Appel LJ, Martin SS. Critical Flaws in the Validation of the Instant Blood Pressure Smartphone App-A Letter from the App Developers-Reply. JAMA Intern Med. 2016.

9. Burke LE, Ma J, Azar KMJ, et al. Current Science on Consumer Use of Mobile Health for Cardiovascular Disease Prevention: A Scientific Statement from the American Heart Association. Circulation. 2015; Vol 132: 1157-213.

10. Fleming S, Atherton H, Mccartney D, et al. Self-screening and nonphysician screening for hypertension in communities A systematic review. Am J Hypertens. 2015; 28(11): 1316-24.

11. Tompson AC, Grant S, Greenfield SM, et al. Patient use of blood pressure self-screening facilities in general practice waiting rooms: A qualitative study in the UK. Br J Gen Pract. 2017; 67(660): e467-73.

12. Tucker KL, Sheppard JP, Stevens R, et al. Self-monitoring of blood pressure in hypertension: A systematic review and individual patient data meta-analysis. PLoS Med. 2017; 14(9).

13. Cairns AE, Tucker KL, Leeson P, et al. Self-Management of Postnatal Hypertension: The SNAP-HT Trial. Hypertens (Dallas, Tex 1979). 2018; 72(2): 425-32.

14. Stojanova A, Koceski S, Koceska N. Continuous Blood Pressure Monitoring as a Basis for Ambient Assisted Living (AAL) - Review of Methodologies and Devices. Journal of Medical Systems. 2019; Vol 43.

15. Kumar N, Khunger M, Gupta A, et al. A content analysis of smartphonebased applications for hypertension management. J Am Soc Hypertens. 2015; 9(2): 130-6.

16. McManus RJ, Mant J, Franssen M, et al. Efficacy of self-monitored blood pressure, with or without telemonitoring, for titration of antihypertensive medication (TASMINH4): an unmasked randomised controlled trial. Lancet. 2018; 391(10124): 949-59.

17. Omboni S, Gazzola T, Carabelli G, et al. Clinical usefulness and cost effectiveness of home blood pressure telemonitoring:Meta-analysis of randomized controlled studies. J Hypertens. 2013; 31(3): 455-68.

18. Levine DM, Dixon RF, Linder JA. Association of Structured Virtual Visits for Hypertension Follow-Up in Primary Care with Blood Pressure Control and Use of Clinical Services. J Gen Intern Med. 2018; 33(11): 1862-7.

19. Dixon RF, Rao L. Asynchronous virtual visits for the follow-up of chronic conditions. Telemed e-Health. 2014; 20(7): 669-72.

20. Sheppard JP, Tucker KL, Davison WJ, et al. Self-monitoring of blood pressure in patients with hypertension related multi-morbidity: Systematic review and individual patient data meta-analysis. Am J Hypertens [Internet]. 2019 Nov 15; Available from: http://www.ncbi. nlm.nih.gov/pubmed/31730171

21. NICE. Hypertension in adults: diagnosis and management [NG136]. 2019.

22. Pérez-Rodríguez G, Brito-Zurita OR, Sistos-Navarro E, et al. Telemetric monitoring reduces visits to the emergency room and cost of care in patients with chronic heart failure. Cirugía y Cir English Ed. 2015; 83(4): 279-85.

23. Varon $\mathrm{C}$, Alao M, Minter J, et al. Telehealth on heart failure: results of the Recap project. J Telemed Telecare. 2015; 21(6): 340-7.

24. Bui AL, Fonarow GC. Home monitoring for heart failure management Journal of the American College of Cardiology. 2012; Vol 59: 97-104.

25. Baert A, Clays E, Bolliger L, et al. A Personal Decision Support System for Heart Failure Management (HeartMan): study protocol of the HeartMan randomized controlled trial. BMC Cardiovasc Disord VO - 18 [Internet]. 2018; (1): 1. Available from: https://ezp.lib. unimelb.edu.au/login?url=https://search.ebscohost.com/login aspx?direct=true $\& \mathrm{db}=$ edsdoj\&AN=edsdoj.b03903cf1364bc8be6aa7 b94eefcf $7 \mathrm{~d} \&$ site=eds-live \&scope=site

26. The George Institute for Global Health. Home monitoring with ITsupported specialist management versus home monitoring alone in patients with heart failure: Design and baseline results of the SUPPORT-HF 2 randomized trial. Am Heart J. 2019; 208: 55-64.

27. Go AS, Hylek EM, Phillips KA, et al. Prevalence of diagnosed atrial fibrillation in adults: National implications for rhythm management and stroke prevention: The anticoagulation and risk factors in atrial fibrillation (ATRIA) study. J Am Med Assoc. 2001; 285(18): 2370-5.

28. Clark CE, McDonagh STJ, McManus RJ. Accuracy of automated blood pressure measurements in the presence of atrial fibrillation: systematic review and meta-analysis. Journal of Human Hypertension. 2019; Vol 33: 352-64.

29. Williams B, Mancia G, Spiering W, et al. 2018 ESC/ESH Guidelines for the management of arterial hypertension: The Task Force for the management of arterial hypertension of the European Society of Cardiology and the European Society of Hypertension: The Task Force for the management of arterial h. J Hypertens VO - 36 [Internet]. 2018; (10): 1953. Available from: https://ezp.lib.unimelb.edu.au/ login?url=https://search.ebscohost.com/login.aspx?direct=true\&db =edsgao\&AN=edsgcl.554824338\&site=eds-live \&scope=site

30. Perez MV, Mahaffey KW, Hedlin H, et al. Large-scale assessment of a smartwatch to identify atrial fibrillation. N Engl J Med. 2019; 381(20): 1909-17.

31. Mackillop L, Hirst JE, Bartlett KJ, et al. Comparing the efficacy of a mobile phone-based blood glucose management system with standard clinic care in women with gestational diabetes: Randomized controlled trial. JMIR mHealth uHealth. 2018; 6(3).

32. Ming WK, Mackillop LH, Farmer AJ, et al. Telemedicine technologies for diabetes in pregnancy A systematic review and meta-analysis. Journal of Medical Internet Research. 2016; Vol 18.

33. Tucker KL, Taylor KS, Crawford C, et al. Blood pressure self-monitoring in pregnancy: Examining feasibility in a prospective cohort study. BMC Pregnancy Childbirth. 2017; 17(1).

34. Sawtell M, Sweeney L, Wiggins M, et al. Evaluation of communitylevel interventions to increase early initiation of antenatal care in pregnancy: Protocol for the Community REACH study a cluster randomised controlled trial with integrated process and economic evaluations. Trials. 2018; 19(1).

35. Hunter LJ, Da Motta G, McCourt C, et al. Better together: A qualitative exploration of women's perceptions and experiences of group antenatal care. Women and Birth. 2019; 32(4): 336-45.

36. Hunter L, Da Motta G, McCourt C, et al. 'It makes sense and it works': Maternity care providers' perspectives on the feasibility of a group antenatal care model (Pregnancy Circles). Midwifery. 2018; 66: 56-63.

37. Dougall G, Franssen M, Tucker KL, et al. Blood pressure monitoring in high-risk pregnancy to improve the detection and monitoring of hypertension (the BUMP 1 and 2 trials): protocol for two linked randomised controlled trials. BMJ Open. 2020

38. Cairns AE, Tucker KL, Crawford C, et al. Implementing selfmanagement: a mixed-methods study of women's experiences of a postpartum hypertension intervention (SNAP-HT). 2020.

39. Gyselaers W, Lanssens D, Perry H, et al. Mobile Health Applications for Prenatal Assessment and Monitoring. Curr Pharm Des. 2019; 25(5): 615-23. 